\title{
Abortion and fertility control in Pakistan: the role of misoprostol
}

\author{
Harneet Chahal, Zubia Mumtaz
}

School of Public Health, University of Alberta, Edmonton, Alberta, Canada

\section{Correspondence to} Dr Zubia Mumtaz, School of Public Health, University of Alberta, 3-309 Edmonton Clinic Health Academy, 11405-87 Ave NW, Edmonton, AB, Canada T6G 1C9; zubia.mumtaz@ualberta.ca

Received 10 December 2015 Revised 30 November 2016 Accepted 16 January 2017 Published Online First 10 February 2017
CrossMark

To cite: Chahal H, Mumtaz Z.J Fam Plann Reprod Health Care 2017;43:274-280.
ABSTRACT
Objective To examine how availability of misoprostol has impacted women's abortionseeking behaviour in Pakistan.

Design Focused ethnography.

Setting A facility providing reproductive health services, including induced abortions in Chakwal, a small town in Northern Punjab, Pakistan.

Population Women who came to the clinic seeking an abortion or who had had one in the last 6 months $(n=23)$ and all healthcare providers working in the facility $(n=14)$.

Methods Semi-structured interviews ( $n=37)$, a focus group discussion ( $n=1)$ and participant observation ( $n=41$ ). Latent content analysis was conducted drawing on principles of constant comparison to generate key themes in reported experiences.

Results All the respondents had sought an abortion to limit their fertility. Although some reported contraceptive use, improper use, undesirable side effects and restrictions on use had led to the unwanted pregnancy. All the women specifically requested misoprostol within days of their pregnancy, suggesting that they not only had knowledge of misoprostol as a backup in case of contraceptive failure, but may have pre-planned its use of in place of using contraception. Women reconciled their decision to undergo an abortion by describing it as a mistake, miscarriage or menstrual cycle issue. Conclusions Misoprostol's availability, ease of use and effectiveness have increased the role of abortion in fertility control.

\section{INTRODUCTION}

Abortion (termination of pregnancy) is on the rise in Pakistan, where recent estimates indicate that the number of abortions increased from 890000 in 2002 to 2.25 million in 2012. ${ }^{1}$ These numbers are surprising, given that abortion in Pakistan occupies an ambiguous legal, religious and social position. Since 1997, Pakistani law has permitted abortion to save a woman's life and to provide

\section{Key message points}

- In a context of low contraceptive use, women sought abortions to limit their fertility.

- Misoprostol's widespread availability, ease of use and effectiveness have enabled women to use abortion to meet their family planning needs.

- It is recommended that policies which involve approved, safe, communitylevel availability of misoprostol are implemented in Pakistan.

'necessary treatment'. ${ }^{3}$ However, no details are given as to whether saving the mother's life also extends to her mental and social wellbeing, and the term 'necessary treatment' is not clarified. This provides flexibility in interpretation of the law for both healthcare providers and women. Similarly, there is a lack of clarity around permissibility of abortion in Islam, with some scholars concluding it is allowed prior to 120 days' gestation, while others deem it a $\sin .{ }^{4}$ Nonetheless, substantial social stigma persists around abortion as women seeking this procedure are often viewed as sexually promiscuous, and violators of gendered and cultural norms. ${ }^{5}$

Given these circumstances, women have traditionally sought clandestine services. $^{3} 6$ While these services offer women a greater degree of confidentiality and some protection from punitive measures, ${ }^{3}$ they are typically administered by poorly trained providers lacking the appropriate equipment and medical training needed to safely perform the procedure. ${ }^{6} 7$ Risks of acute and long-term complications such as damage to reproductive organs and secondary infertility are elevated in such unsafe settings. ${ }^{8}$ The impact of this is visible in the 623000 
women who obtained post-abortion care for complications of unsafe abortion in 2012. ${ }^{9}$

There is, however, potential for the abortion landscape in Pakistan to change with the availability of the drug misoprostol. This drug was originally developed in the mid-1980s for treatment of duodenal and gastric ulcers. ${ }^{10}$ As a prostaglandin analogue, it also induces uterine contractions and cervical softening, making it an effective agent for emptying uterine contents. ${ }^{10} 11$ Numerous studies have shown its efficacy for terminating pregnancies, inducing labour, and prevention and treatment of postpartum haemorrhage. ${ }^{12} 13$ The usefulness of misoprostol as an abortifacient is enhanced by its oral administration at home and fewer reported complications and hospital stays as compared to surgical procedures. ${ }^{8} 13$

In Pakistan, misoprostol has been used for hospitalbased induction of labour and uterine evacuation since the 1990s. ${ }^{14}$ It was not, however, until 2012, after misoprostol was put on the 16th World Health Organization Model List of Essential Medicines, that Pakistan permitted its availability in the country for prevention and treatment of postpartum haemorrhage and management of incomplete abortion. ${ }^{14}$ In 2014, clinical protocols for use of the drug were endorsed by all provincial health departments and the drug's use was included in Pakistan's nursing, community midwifery and community health worker training curriculum. $^{3} 715$

Given that misoprostol is a relatively new addition to Pakistan's health system, little is known about how women have responded to its use as an abortifacient, an off-label use in this context. A small body of literature has touched upon the possibility that couples may be opting for abortion to control their fertility. ${ }^{1} 1617$ While misoprostol use is increasing, exactly how it fits within the new context of a smaller preferred family size, ${ }^{18}$ low contraceptive use $^{19}$ and increasing prevalence of abortion ${ }^{1}$ is poorly documented. To address this gap in knowledge, this study sought to understand how the availability of misoprostol has impacted women's abortion-seeking behaviour in rural Punjab, Pakistan.

\section{METHODS}

This article draws on a focused ethnography conducted from September-December 2013. This method was chosen because it allowed development of a holistic understanding of misoprostol availability and use. $^{20}$ Data were collected in the town of Chakwal, Pakistan, a relatively well-developed district as indicated by a literacy rate of $57 \%$ (compared to a national literacy rate of 58\%). ${ }^{21}$ Specifically, data were collected in the Chakwal Rahnuma Family Planning Association of Pakistan clinic. This non-governmental clinic has cautiously taken advantage of Pakistan's ambiguous legal and religious rules around abortion, to provide safe, institutionalised abortion services. A key component of Rahnuma's 2010-2014 Strategic Plan was abortion care. ${ }^{22}$ All the clinic's staff had received training on the provision of abortion as an expected element of the care they were to provide.

Study respondents comprised the first 23 women who consecutively came to the clinic either seeking an abortion (8/23), or seeking post-abortion care/family planning care after having had an abortion within the last 6 months $(15 / 23)$. The latter group was split between those who had an abortion at the Rahnuma clinic and those who had obtained one elsewhere (most often through an untrained provider, such as a Dai, or self-induced). Table 1 lists the characteristics of the 23 patient respondents.

In addition, three obstetrician gynecologists, one nurse, seven female health visitors and three midwives working in the facility were included in the study.

Data were collected using semi-structured interviews, participant observation and a focus group discussion. All respondents underwent an in-depth interview to explore the reasons women sought abortions, the methods used to induce abortion, and the challenges of seeking/ providing care within Pakistan's restrictive setting. Each interview lasted 20-30 minutes and was conducted in a private room in the clinic to ensure privacy and confidentiality. Oral

Table 1 Characteristics of patients

\begin{tabular}{|c|c|}
\hline Characteristic & Patients $(n)$ \\
\hline \multicolumn{2}{|l|}{ Dominant religion } \\
\hline Islam & 23 \\
\hline Other & 0 \\
\hline \multicolumn{2}{|l|}{ Marital status } \\
\hline Married & 23 \\
\hline Unmarried & 0 \\
\hline \multicolumn{2}{|l|}{ Family structure } \\
\hline Nuclear & 7 \\
\hline Extended & 11 \\
\hline Not discussed & 5 \\
\hline \multicolumn{2}{|l|}{ Patients' age (years) } \\
\hline $20 \mathrm{~s}$ & 10 \\
\hline $30 \mathrm{~s}$ & 8 \\
\hline $40 \mathrm{~s}$ & 2 \\
\hline $50+$ & 1 \\
\hline Not discussed & 2 \\
\hline Living children ( $n$ ) & 1 \\
\hline 1 & 4 \\
\hline 2 & 3 \\
\hline 3 & 9 \\
\hline 4 & 6 \\
\hline $5+$ & 1 \\
\hline \multicolumn{2}{|l|}{ Abortions (n) } \\
\hline 1 & 21 \\
\hline 2 & 0 \\
\hline 3 & 1 \\
\hline $4+$ & 1 \\
\hline
\end{tabular}


consent was obtained and the discussions were digitally recorded. One focus group discussion (FGD) was conducted with five providers. This offered an opportunity to clarify and supplement ideas brought forth by patients and providers during their interviews. Observing patient-provider interactions and engaging in informal interactions with patients in waiting rooms enabled comparison of what respondents discussed individually versus their practice. A total of 41 such sessions were recorded. Field notes and a reflexive journal were used to record contextual information and participant behavioural nuances observed during the interviews. ZM, the senior author, has a wellestablished research programme in district Chakwal, which enabled access to Rahnuma's clinic. HC, the first author, is fluent in Punjabi and Urdu, the local languages. Together with a local research assistant, and constant presence in the facility for 4 months, HC was able to build a rapport with both patients and provider respondents. This enabled collection of sensitive data.

All interviews, the FGD and observation recordings were translated and transcribed into English by HC. A database of all transcripts was created. Data were analysed concurrent to, and following, data collection through a latent content analysis approach. ${ }^{20}$ This approach allowed us to understand the meaning of our data in the specific context of the setting in which the study took place. ${ }^{20}$ Descriptive codes were developed throughout the transcription process, then again by reading and re-reading transcripts once they were complete. These were then categorised to identify broader themes, to abstract deeper meaning, and to develop an explanation for the findings. Data from interviews, the FGD and observation notes were merged to describe the experiences of patients and providers in accessing and providing abortion services, respectively.

An audit trail using personal memos and journaling was maintained throughout the research process to ensure dependability and confirmability. Interpretive accuracy was assessed by triangulation of findings, peer debriefing within the research team and with other colleagues. $^{20}$

Ethical clearance was obtained from the University of Alberta Research Ethics Board, and the National Bioethics Board, Pakistan.

\section{FINDINGS}

We identified three themes in the data that could broadly be understood as: (1) women sought abortions to limit their fertility; (2) misoprostol enabled women to meet their fertility needs; and (3) ways in which women reconciled their decision to use abortion in this manner.

\section{Women sought abortions to limit their fertility}

All 23 patient respondents who sought or had an abortion did so to limit their fertility. Over half (13/ 23) of these women had used modern contraceptives in a proactive effort to prevent pregnancy. However, contraceptive failure was commonly cited as a reason for the unplanned pregnancy. Condoms were the most commonly reported failed method, although birth control pills and intrauterine devices (IUDs) were also cited. In a few cases, contraceptive failure was a result of inappropriate use of the contraceptive method, as indicated by women reporting they were not aware that birth control pills need to be taken daily. As one woman said:

"My sister in law, she eats [her birth control pills] every 3 days, three pills at a time ... she says it makes her feel sick so she eats three every 3 days." [Patient 7]

Other women reported undesirable side effects including heavy and persistent bleeding, disrupted or absent menses, and pain and weakness as the cause of discontinued use.

"Sometimes I would bleed continuously for 2 months at a time ... the third time I got scared, I thought this time I will not get the injection done." [Patient 14]

Women typically tolerated such discomforts for several months before finally deciding they had had enough, and ceasing further use. While most switched methods, it was often in the gap between discontinuing one method and seeking another that women became pregnant.

The remaining respondents (10/23) reported not having used any family planning method, either because of their husbands' restrictions, or because they had simply overlooked the need. Husbands restricted use either because of beliefs that contraceptives might have negative consequences for their wife's health or physical beauty, or that it was a sin. Older women and those who did not live with their husbands assumed they did not need to use protection. A small group expressed no interest in using any contraception, leaving it to 'Allah'. The fact that they were seeking an abortion suggested that they preferred to address the issue of an unplanned pregnancy, if and when they conceived.

\section{Misoprostol allowed women to meet their fertility needs} Our data suggest that where women wanted to control their family size but were either unsuccessful or had not proactively used any form of contraception, they turned to abortion. Specifically, women expressed a strong preference for misoprostol. Although none could name it precisely, they explicitly asked for the pill that can terminate a pregnancy. Among the 3/23 women who had an abortion by means of other methods, they either attempted to use misoprostol first or wished they had been given misoprostol instead.

"At the time of getting an abortion [with D\&C] ... that's when I lost consciousness ... She did not give me the pill, that's the problem. She used the tool, because of that I had a lot of trouble." [Patient 5] 
Further analysis of our data suggests that availability of misoprostol may in fact have begun to factor into our respondents' family planning and contraceptive use decisions. Most women actively sought the drug within days of realising they were pregnant. The fact that they came to the clinic specifically seeking misoprostol (so soon after this realisation), points to the possibility that they not only had knowledge of misoprostol as a backup to when contraception failed, but may in fact have preplanned its use of in place of a contraceptive. Women appeared to have made up their minds to use the drug, remaining resistant to any alternate suggestion.

This possibility was echoed by providers who commented that although their clients wished to limit their family size or space pregnancies, proactive use of contraception was missing. According to this group, abortion was viewed by their clients as an easier alternative to contraceptive use. The widespread availability of misoprostol not only made this possible, it also relieved women of the responsibility to prevent pregnancy. Instead, a simple orally ingested pill could now terminate an unwanted or unplanned pregnancy, if and when it occurred.

Women have started preferring the option of abortion; they don't like using family planning methods. The reason is there are myths that if we get a copper-T put in, it will go up, it won't be able to come out. From that you can get cancer ... this and that. They say all these things which in reality have no truth. Understand? The depo [Depo-provera ${ }^{\circledR}$ ] will cause my periods to stop, or it will cause an excess amount of bleeding, so these types of things." [Provider]

\section{Misoprostol made abortions practical, accessible and easier}

Our data provided a number of explanations as to why misoprostol had possibly become a form of fertility control. First, it enabled women to reactively respond to a pregnancy if and when it occurred instead of having to use a contraceptive that required the husband's, and possibly the in-law family's, permission and cooperation. One woman, who attended for her sixth abortion, cited an abusive husband and regular rape for her decision. Unable to use any form of family planning, using misoprostol to induce her unwanted pregnancies was her only option for maintaining any control over her life. Second, misoprostol freed women from having to take a daily pill or suffer the many side effects of injections and IUDs.

Misoprostol was also widely and easily available. While our respondents sought abortion services from a clinic, they indicated that the drug was easy to obtain over the counter, or through social networks, such as female relatives. It was affordable, costing Pakistan Rupees (PKR) 100 (equivalent to $£ 0.77$ GBP) compared to PKR 3500 ( $£ 26.67)$ for an abortion using traditional surgical methods. This availability of misoprostol within the community also eliminated the need to travel to a clinic, a crucial variable in a context such as Pakistan where gendered norms limit women's mobility. ${ }^{23}$

"They eat the pills and that's it .... there is no need to come here to the clinic, nor is there any issue of getting home." [Provider Sh, LHV]

Even where patients did seek the pill from a trained provider, misoprostol had the benefit of creating a separation between providers and the actual abortion procedure. Providers were no longer needed to physically participate in inducing the abortion, which was in sharp contrast to traditional methods such as dilation and curettage (D\&C) or manual vacuum aspiration.

Abortion using misoprostol was also perceived by patients to be a safer way to terminate a pregnancy. Women understood that an abortion requiring instrumental removal of the fetus was a dangerous procedure, especially when conducted by a Dai:

\section{"These Dai's, you never know what they can put inside you.” [Patient 25]}

Misoprostol, as an oral pill, obviated the need for such invasive procedures, and was seen by patients as being comparable in effectiveness to traditional surgical methods. Furthermore, all the women who had an abortion with misoprostol reported that it was successful within a week of its use.

\section{Reconciling the pursuit of abortion}

A key question that arises is how do women reconcile their decision to undergo an abortion when dominant beliefs stigmatise abortion as immoral and illegal? Our data showed that all respondents avoided discussion around the morality of their decision. Upon probing, only two respondents explicitly indicated regret towards pursuing the procedure, stating they knew the procedure was viewed as a sin, or simply that they had made a mistake, and would begin 'treatment', namely use of some form of contraception after the termination was completed:

\section{"We just made a mistake. After this I will get the treat- ment done....” [Patient 13]}

Some patients gradually transformed recollections of their induced abortion into a spontaneous abortion. Since the local term for the word abortion is 'zaya', which translates closest to 'waste', the term was ambiguously used for both termination of pregnancy and miscarriage. Thus a subtle change in language was sufficient to change perceived reality. A woman, previously self-identified as having had an abortion, gradually altered her description to that of a miscarriage as the interview progressed:

\footnotetext{
"It terminated, meaning bleeding started ... It happened on its own." [Patient 15]
} 
Nonetheless, our observations showed that most women had come to clinic with their minds made up. They knew they wanted to terminate their unplanned pregnancy and they came to the clinic fully prepared with their reasons for wanting an abortion. No amount of counselling against their decision was sufficient to change their minds.

\section{DISCUSSION}

The key finding of this study is that the ease of use and effectiveness of this off-label use of misoprostol has not only made abortions easy, but may be transforming the procedure into a preferred fertility control strategy in our field site. All the study respondents sought abortions for unwanted pregnancies as a result of either contraceptive failure, discontinued use due to unacceptable side effects or simply because of not using any method. That societies undergoing fertility transition are characterised by not only increased contraceptive use, but also increased abortion rates is a well-documented phenomena worldwide. ${ }^{24}$ Although startling, the finding that women are using abortion as a method of family planning is not new. It aligns with an emerging body of literature by Khan et al., ${ }^{19}$ Saleem and Fikree, ${ }^{16} 17$ and Rehan et al. ${ }^{25}$ that suggests women in Pakistan may be opting for abortion to attain their goals for a small family size in place of preventive contraception. Together these quantitative survey-based studies, paired with well-documented rising rates of misoprostol use, ${ }^{26}$ suggest the possibility of using abortion as a method of family planning. Our study adds qualitative insight to these finding, and confirms that misoprostol is the key element providing women with the means to do so.

The disquieting nature of this finding, however, namely that abortion is being used as a method of family planning, in preference to modern contraceptive methods, raises more questions. Are women being forced to resort to abortion because they do not have access to modern contraceptives? Or are the side effects of these contraceptives so unacceptable that women would rather seek an abortion than suffer the side effects? Poor family planning service delivery in Pakistan has been documented as the reason underlying low contraceptive use rates. ${ }^{7}$

At the same time, however, $55 \%$ of women in Pakistan report having ever used a family planning method. ${ }^{21}$ In other words, over half the eligible women have accessed family planning services, suggesting that a lack of family planning services delivery may not be the only reason for low contraceptive use. Unacceptable side effects remain a key reason for discontinuation. Tsui ${ }^{27}$ suggests that in contexts where a strong social taboo is attached to infertility, women's hesitancy towards using modern contraceptives stems from a belief that they may lead to an inability to have children in the future. Women become even more reluctant to use a contraceptive when they experience discomfort. ${ }^{28}$ Our data suggest that side effects are so unacceptable that women would rather seek an abortion for an unwanted pregnancy than put up with the perceived dangers of modern contraceptive methods. While the option of an abortion had not been practical when it required minor surgery with attendant expenses, the easy availability, effectiveness and safety of misoprostol has made it possible.

Misoprostol has also given women greater control over their reproductive decisions. As it can be obtained independently of husband or provider, misoprostol has reduced women's dependence on their families and providers, and thereby provided them with greater autonomy regarding their reproductive needs. ${ }^{29}$ Even where patients sought the drug from a trained provider, misoprostol created a separation between the provider and the actual abortion procedure. This was beneficial to patients because whereby a provider may have been morally opposed to conducting an abortion, misoprostol offered a way to balance providers' beliefs with patients' health needs. These advantages of misoprostol have been described elsewhere in the South Asian context, such as in Nepal. ${ }^{30}$

This reproductive autonomy conferred by misoprostol seems to parallel that provided by the birth control pill to women in Western countries. Credited with leading the sexual revolution of the 1960s in the USA, England and West Germany, the pill enabled women to delay or space pregnancies as they wished. ${ }^{31}$ The pill did not lead to a similar revolution in Pakistan, possibly because Pakistani women were much more reluctant to use the birth control pill. ${ }^{27} 28$ Our data, however, suggest women in Pakistan appear to find misoprostol much less intimidating. We tentatively argue that misoprostol in Pakistan has taken on a role equivalent to oral contraception in the Western world in the 1960s, in that it is allowing women greater reproductive autonomy.

Ultimately though, abortion remains a heavily stigmatised procedure in Pakistan. Irrespective of how women managed their guilt, by the time they came to the clinic to obtain an abortion their minds were made up. This demonstrated that women's desire to limit their family size was so strong that it outweighed the morally contentious space that abortion occupied and motivated them to overcome any reluctance they had in undergoing a 'sinful' procedure. Arif and $\mathrm{Kamran}^{32}$ have reported similar findings, namely that the social costs of being stigmatised do not restrict women from undergoing induced abortion when they are determined.

\section{Interpretations}

The findings of our research have important implications for scaling-up access to safe abortion services to avert preventable maternal morbidity and mortality associated with unsafe abortion. This includes training 
community midwives and community health workers to administer misoprostol within women's homes and teaching them about the legality of doing so under the legislative framework of Pakistan. There is also a need to create teaching materials suitable for a low literacy audience, that describe the proper use of the drug. ${ }^{33}$ Finally, it is of great importance to address barriers to contraceptive uptake, a problem that Pakistan has yet to tackle.

\section{Strengths and limitations}

Limitations of the study include a possible socialdesirability bias. Patients may have attempted to better align their actions with social norms by inflating their recollection of contraceptive use (such as the number of methods tried) and under-reporting the number of abortions they had. We did, however, probe into patient responses to assess whether patients were being authentic in their recollection of the types of contraceptives they had used, and what led to either their discontinuation or failure. Selection bias was another limitation of this study. Given the sensitive nature of abortion, sampling outside a clinic or hospital setting is extremely difficult. Thus women who seek clandestine abortion services were, for the most part, not accessed by this study. Furthermore, given that this study was conducted only in the province of Punjab, there are dangers in extrapolating and generalising findings nationally. Nevertheless, it is likely that the broad conclusions presented here are of relevance elsewhere in Pakistan (beyond Chakwal) and in other settings where restrictions around abortion exist and misoprostol is available.

\section{CONCLUSION}

Misoprostol has provided women in Pakistan with a more practical and accessible means of fertility control.

Acknowledgements The authors wish to thank the study participants in Chakwal for their generosity and time. They also thank the Rahnuma Family Planning Association in Pakistan, and specifically Ms Asifa Khanum. They wish to thank their Research Assistant, Ms Zakia. Finally, they wish to thank Ms Afshan Bhatti of the Real Medicine Foundation for her support and guidance, and for welcoming HC into her home during field work in Pakistan.

Funding The study was funded by the Canadian Institutes of Health Research Grant No. 21376-CIHR. ZM is currently funded by Alberta Innovates Health Solutions through its Alberta Heritage Foundation for Medical Research Population Health Investigator Awards.

Competing interests None declared.

Ethics approval University of Alberta Research Ethics Board, and the National Bioethics Board, Pakistan.

Provenance and peer review Not commissioned; externally peer reviewed.

Data sharing statement The authors are happy to share their data. They hope to publish a further paper based on the dataset; this second paper is ready for submission.

\section{REFERENCES}

1 Vlassoff M, Singh S, Suarez G, et al. Abortion in Pakistan. In Brief. New York, NY: Guttmacher Institute 2009; No. 2.

2 Patel R. Woman versus Man: Socio-Legal Gender Inequality in Pakistan. Karachi, Pakistan : Oxford University Press, 2003.

3 Zaidi S, Begum F, Tank J, et al. Achievements of the FIGO Initiative for the Prevention of Unsafe Abortion and its Consequences in South-Southeast Asia. Int J Gynecol Obstet 2014;126:S20-S23.

4 Jafri $\mathrm{H}$, Ahmed S, Ahmed M, et al. Islam and termination of pregnancy for genetic conditions in Pakistan: implications for Pakistani health care providers. Prenat Diagn 2012;32:1218-1220.

5 Ashforth BE, Kreiner GE. "How can you do it?": dirty work and the challenge of constructing a positive identity. Acad Manag Rev 1999;24:413-434.

6 Sathar Z. Stagnation in fertility levels in Pakistan. Asia Pac Popul J 2007;22:113-131.

7 Sathar Z, Rashida G, Shah Z, et al. Postabortion care in Pakistan. 2013. https://www.guttmacher.org/report/ postabortion-care-pakistan [accessed 9 June 2015].

8 Berer M. Making abortions safe: a matter of good public health policy and practice. Reprod Health Matter 2002;10:31-44.

9 Sathar Z, Singh S, Rashida G, et al. Induced abortions and unintended pregnancies in Pakistan. Stud Family Plann 2014;45:471-491.

10 Billings DL. Misoprostol alone for early medical abortion in a Latin American clinic setting. Reprod Health Matter 2004;12:57-64.

11 World Health Organization [WHO]. Safe Abortion: Technical and Policy Guidance for Health Systems. Geneva, Switzerland: WHO, 2012.

12 Lokugamage AU, El Refaey H, Rodeck CH. Misoprostol and pregnancy: ever-increasing indications of effective usage. Curr Opin Obstet Gyn 2003;15:513-518.

13 Berer M. Medical abortion: issues of choice and acceptability. Reprod Health Matter 2005;13:25-34.

14 Zaidi S, Yasmin H, Hassan L, et al. Replacement of dilation and curettage/evacuation by manual vacuum aspiration and medical abortion, and the introduction of postabortion contraception in Pakistan. Int J Gynecol Obstet 2014;126: S40-S44.

15 Sarwar Z, Cutherell A, Noor A, et al. Analysis of misoprostol and chlorhexidine policy gains in Pakistan: the advocacy experience of Mercy Corps Pakistan. Health Res Policy Syst 2015;13(Suppl. 1):50.

16 Saleem S, Fikree FF. Induced abortions in low socio-economic settlements of Karachi, Pakistan: rates and women's perspectives. J Pak Med Assoc 2001;51:275-279.

17 Saleem S, Fikree FF. The quest for small family size among Pakistani women - is voluntary termination of pregnancy a matter of choice or necessity? J Pak Med Assoc 2005;55:288-291.

18 Sathar Z. Induced Abortions and Unintended Pregnancies in Pakistan, 2012. 2014. http://www.popcouncil.org/uploads/pdfs/ 2014RH_PostabortionCare_Pakistan.pdf [accessed 9 June 2015].

19 Khan AA, Khan A, Javed W, et al. Family planning in Pakistan: applying what we have learned. J Pak Med Assoc 2013;63 (Suppl. 3):S3-S10.

20 Mayan MJ. Essentials of Qualitative Inquiry. Walnut Creek, CA: Left Coast Press, 2009. 
21 National Institute of Population Studies (NIPS) [Pakistan], and ICF International. Pakistan Demographic and Health Survey 2012-2013. Islamabad, Pakistan, and Calverton, MD, USA: NIPS and ICF International, 2013.

22 Rahnuma Family Planning Association of Pakistan [R-FPAP]. Program and Governance, 2015. http://www.fpapak.org/ about-us.html [accessed 9 June 2015].

23 Mumtaz Z, Salway S. 'I never go anywhere': extricating the links between women's mobility and uptake of reproductive health services in Pakistan. Soc Sci Med 2005;60:1751-1765.

24 Marston C, Cleland J. Relationships between contraception and abortion: a review of the evidence. Int Fam Plan Perspec 2003;29:6-13.

25 Rehan N, Inayatullah A, Chaudhary I. Characteristics of Pakistani women seeking abortion and a profile of abortion clinics. J Women Health Gend Based Med 2001;10:805-810.

26 Fernandez MM, Coeytaux F, de León RGP, et al. Assessing the global availability of misoprostol. Int J Gynecol Obstet 2009;105:180-186.

27 Tsui AO, Casterline J, Singh S, et al. Managing unplanned pregnancies in five countries: perspectives on contraception and abortion decisions. Glob Public Health 2011;6(Suppl. 1): S1-S24.

28 Arif MO, Fatmi Z, Pardeep B, et al. Attitudes and perceptions about prenatal diagnosis and induced abortion among adults of Pakistani population. Prenat Diagn 2008;28:1149-1155.

29 Winikoff B, Sheldon W. Use of medicines changing the face of abortion. Int Perspect Sex Reprod Health 2012;38:164-166.

30 Puri M, Lamichhane P, Harken T, et al. "Sometimes they used to whisper in our ears": health care workers' perceptions of the effects of abortion legalization in Nepal. BMC Public Health 2012;12:297.

31 Silies EM. Taking the Pill after the 'sexual revolution': female contraceptive decisions in England and West Germany in the 1970s. Eur Rev Hist 2015;22:41-59.

32 Arif S, Kamran I. Exploring the Choices of Contraception and Abortion Among Married Couples in Tret, Rural Punjab, Pakistan. Islamabad, Pakistan: Population Council, 2007.

33 Bracken H, Family Planning Association of India (FPAI)/ Gynuity Health Projects Research Group for Simplifying Medical Abortion in India. Home administration of misoprostol for early medical abortion in India. Int J Gynecol Obstet 2010;108:228-232. 